\title{
Watch out for trends: did ozone increased or decreased during the COVID-19 pandemic?
}

\author{
Ronan Adler Tavella ${ }^{1}$ Flávio Manoel Rodrigues da Silva Júnior ${ }^{1}$ (i)
}

Received: 26 August 2021 / Accepted: 18 October 2021 / Published online: 25 October 2021

(c) The Author(s), under exclusive licence to Springer-Verlag GmbH Germany, part of Springer Nature 2021

\begin{abstract}
Restriction measures against COVID-19 caused the environmental panorama of cities to change, especially in relation to air pollution. This scenario of severe reduction in the emission of air pollutants led to a flurry of studies about their behavior during the pandemic. The vast majority of studies pointed to a decrease in all pollutants, with the exception of ozone. However, was this highlighted ozone trend really the global trend? This discussion seeks to answer this question while addressing two major considerations that led to this trend: (1) the process of ozone formation and behavior and (2) the main reasons that led to the findings of this trend (region of the studies, meteorological conditions, and the time scale adopted for data collection). From our observations, we emphasize that a trend is not unanimity! The global trend turned out to be the opposite of what the initial studies showed, all this because the observed trend was a regional trend, affected by the reasons discussed. Thus, we raise awareness and concern with the way in which the initial "fever" of the behavior of air pollutants occurred and also toward the act of sampling highly populated areas, as this attitude could have caused biased estimations and disinformation.
\end{abstract}

Keywords SARS-Cov-2 Air pollution $\cdot$ Global trend

\section{Introduction}

To slow the dissemination of coronavirus disease 2019 (COVID-19), numerous countries worldwide have adopted restriction measures that severely limited personal mobility, leading to reductions in overall economic activity (Chinazzi et al. 2020). These restrictions on every day human activity were designed to alleviate the strain on the health care system from COVID-19 and, although these restrictions were primarily meant to flatten the COVID-19 infection curve, they created a unique test bed to assess the effect of anthropogenic activities on air pollution (Diffenbaugh et al. 2020). Space agencies such as European Space Agency (ESA) and the National Aeronautics and Space Administration (NASA) were the first to report significant reduction in air pollutants during China and Italy lockdown measures (ESA 2020; NASA 2020).

Responsible Editor: Lotfi Aleya

Flávio Manoel Rodrigues da Silva Júnior

f.m.r.silvajunior@gmail.com

1 Universidade Federal Do Rio Grande - FURG, Av. Itália km 8 Bairro Carreiros, Rio Grande, RS 96203-900, Brazil
The virus spread in an extremely agile manner, leading, in a few months, more than $90 \%$ of the countries in the world to some type of restriction measures (Fig. 1) (Oxford COVID19 government response tracker-Hale et al. 2020). As these measures were adopted, some obvious and immediate environmental effects were reflected in world reports, mainly with regard to improving air quality/reducing air pollution, causing an almost linear and direct relationship between the start of lockdown measures in a region and the initiation of study submissions and researcher collaboration on the effects of COVID-19 on air pollution in the same given region (Fry et al. 2020; Tavella and Da Silva Júnior 2020; Zhang et al. 2021).

In summary, most studies that investigated the impact of restriction measures on air pollution presented a characteristic behavior, where the most widely reported pattern was a reduction in $\mathrm{NO}_{2}$ levels and a consequent increase in ozone levels $\left(\downarrow \mathrm{NO}_{2}, \uparrow \mathrm{O}_{3}\right.$ ) (i.e., Bao and Zhang 2020; Berman and Ebisu 2020; Dantas et al. 2020; Nakada and Urban 2020; Tobías et al. 2020), which were almost always associated with the reduction of other pollutants such as $\mathrm{PM}_{10}, \mathrm{PM}_{2.5}$, $\mathrm{CO}$, and $\mathrm{SO}_{2}$. Following this trend, and what was highlighted by the majority of studies, we can observe that only 


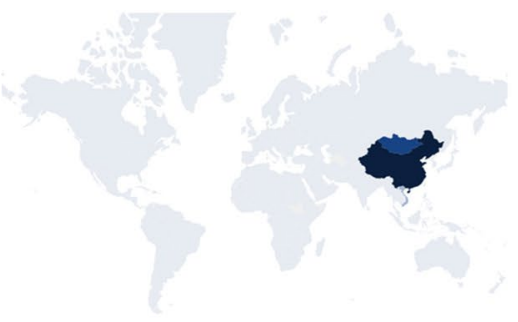

02 January 2020

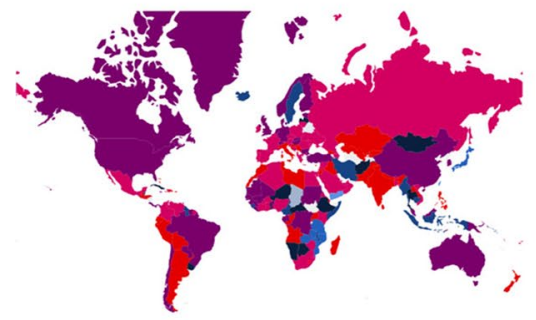

30 March 2020

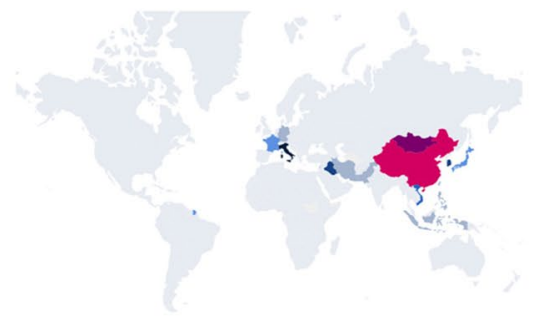

28 February 2020

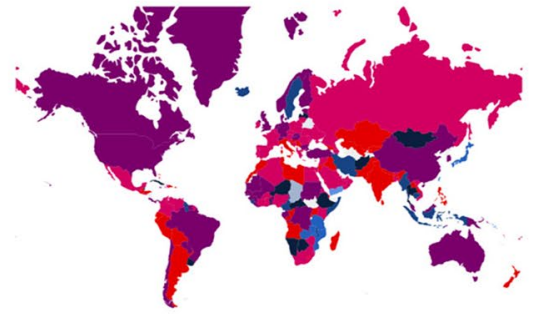

30 April 2020

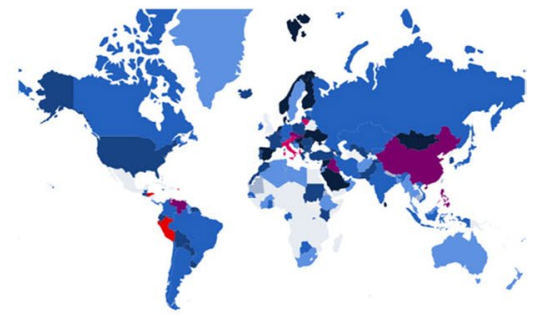

15 March 2020

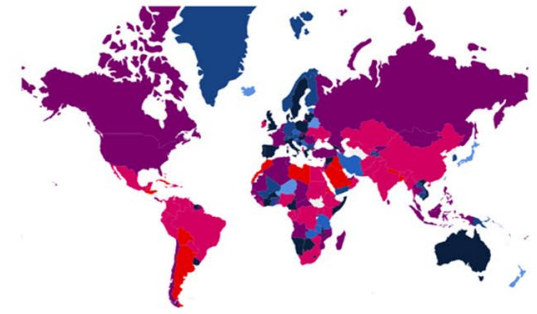

30 May 2020

Government response strategy index

Weak stringency
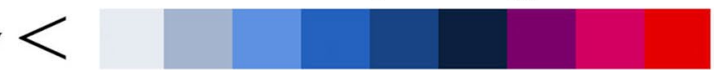

$>$ Strong stringency

Fig. 1 Stringency levels on the government response strategy index around the globe on six different dates between 02 January and 30 May 2020 (The Oxford Government Response Stringency Index — Hale et al. 2020)

ozone, among the criteria air pollutants, increased. However, was this highlighted trend for ozone really the global trend?

This is an important and intriguing question, because the tendency toward sampling highly populated areas during the COVID-19 restriction measures could have led to biased estimations when extrapolating from regional to global scales because of local effects. Thereby, in order to answer this question clearly, it is important to elucidate two considerations: the first is the formation process and behavior regime of this pollutant and the second are the main reasons that led to the findings of this trend.

\section{Formation and behavior of ozone}

First of all, ozone is one of the most complex chemical species in the atmosphere. It is formed during daytime by nonlinear chemical processes at a rate that is determined by the atmospheric concentrations of volatile organic compounds (VOCs) and nitrogen oxides (NOx), as observed in Fig. 2. At low NOx levels, in remote or weakly polluted areas, ozone production is controlled (or limited) by the concentration of NOx. In this case, NOx regulates the rate of the $\mathrm{RO}_{2}+\mathrm{NO}$ reaction, which controls radical propagation. Ozone reacts primarily through reactions involving hydrogenated species that lead to the formation of hydrogen peroxide, which is eventually scavenged by wet and dry deposition. However, in environments with very high levels of NOx, that is, in heavily polluted areas including industrial and urban complexes, nitrogen oxides act as a sink for the $\mathrm{OH}$ radical, which is capable of slowing down the oxidation of VOCs and hence the formation of peroxy radicals. Following this behavior, ozone production ends up being considerably reduced. Rather, ozone is sequestered by NO to form $\mathrm{NO}_{2}$, which after further reactions is converted to nitric acid and removed from the atmosphere by the same behavior as the aforementioned hydrogen peroxide. This situation is referred to as VOC-controlled (or limited) conditions (Sillman 1999; Gaubert et al. 2021).

In this context, the reduction in VOCs and NOx during the pandemic is expected to have led to a reduction of ozone in NOx-limited regions (regions with low levels of NOx), but to have caused an increase in the ozone concentration in the most polluted areas, especially during winter when the levels of NOx are the highest. This guides our argument to the second important considerations in this discussion: the region of the studies regarding air pollution/COVID-19; the meteorological conditions; and the 


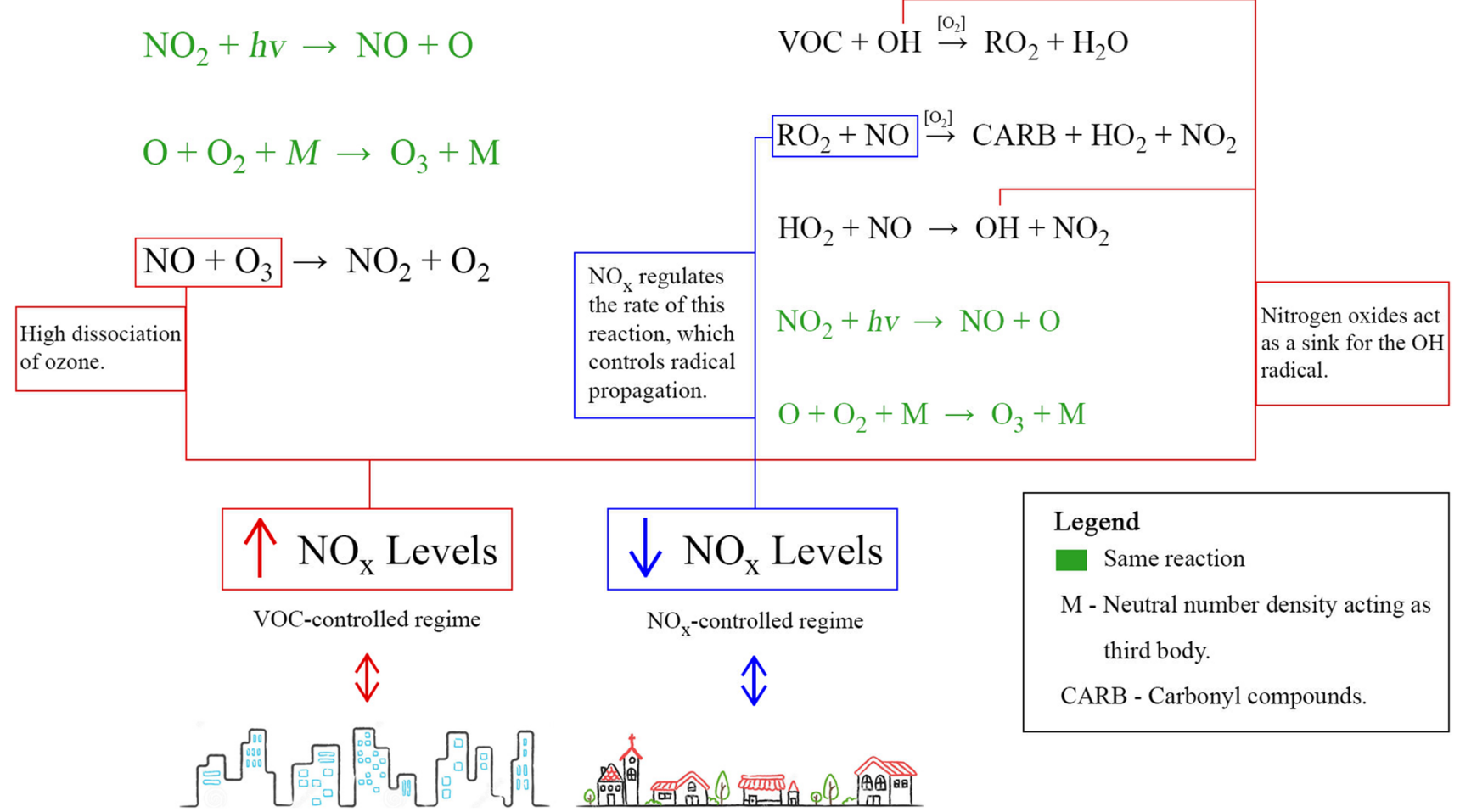

Fig. 2 Formation and behavior of ozone upon NOx concentration in different regions

time scale adopted for data collection. It is important to emphasize that these conditions are intrinsically linked to the studies that observed a decrease in ozone levels.

\section{Main reasons that led to this trend}

It is a fact that the vast majority of studies investigating changes in air quality to the detriment of actions against COVID-19 occurred in highly populated areas, ranging from large cities to metropolitan regions. This action, even if unconsciously, based on the principle that populous regions would generate more pronounced results and of greater interest to the global community, caused the pattern of findings to show a tendency of decrease in the concentration of ozone, following the predicted in the "Formation and behavior of ozone" section. In addition to the level of air pollutants emissions in populated areas, meteorology significantly influences the air quality in a given region, because it directly affects the physical and chemical processes caused in its atmosphere (Sathe et al. 2021). Furthermore, ozone is strongly influenced by variables such as light intensity, humidity, and temperature (Sillman 1999). Moreover, air pollution concentrations at a given location vary on time scales from seconds to years; some variability is random or quasi-random, another variability is systematic (i.e., non-random). Temporal variability is caused by changes in emissions and meteorology and their associated impacts on rates of transport, production, removal, and dilution (Bekbulat et al. 2021). Hence, any changes in air quality require analysis at different scales vis-à-vis changes in emissions, meteorology, atmospheric chemistry, and temporal variability.

To our knowledge, few (9) were the studies that observed and highlighted the decrease in ozone concentration during restriction measures. However, surprisingly, after careful analysis, it is possible to note that the authors attributed their findings to three main reasons: (1) the location where the study was carried out (Dentener et al. 2020; Tavella et al. 2021); (2) the observed meteorological conditions (Adams 2020; Korhale et al. 2021); and (3) the period of time used to obtain the data (Bekbulat et al. 2021; Miyazaki et al. 2021; Sathe et al. 2021; Steinbrecht et al. 2021; Querol et al. 2021;). Interestingly, the same reasons that lead to the variability of this compound in the air matrix were those observed when the study pattern was changed (i.e., smaller cities and/or longer data collection and analysis period). In addition to these, numerous studies did not observe an increase or decrease in ozone (i.e., Chen et al. 2020; Keller et al. 2021; Menut et al. 2020 [...]); however, as a criterion to maintain the direction of our discussion, we will focus on what was pointed out by the studies that verified a decrease. 
First, the region of the study directly affecting the behavior of ozone levels after the implementation of the restriction measures is expected, directly following the relationship presented in the "Formation and behavior of ozone" section. It is interesting to note that even in a medium-sized city, with approximately 200 thousand inhabitants, the behavior presented by ozone is characteristic of a NOx-controlled regime (Tavella et al. 2021), giving dimension to the amount of emission of air pollutants necessary to establish the VOCcontrolled regime.

Second, the spread of the virus and the beginning of the implementation of the restriction measures took place in the first months of the year 2020 and in countries of the Northern Hemisphere. This situation meant that the studies performed in these countries during this period were in winter, a season recognized for presenting the highest levels of NOx (Gaubert et al. 2021), which could put even more pressure on some regions to a VOC-controlled regimen. Including, it may even lead to an impaired pollutant baseline if evaluated only against a few months earlier, demonstrating here the importance of approaching historical data (from a set of multiple earlier years) to avoid this. In addition, the appropriate recommendation in the case of air quality studies/COVID-19 would be to carry out a statistical treatment aimed at canceling the meteorological effect, thus exposing the reality of the situation of air pollutants in view of the adoption of restriction measures only. In this regard, we emphasize the study by Ordóñez et al. (2020) which, in addition to noting both positive and negative changes in ozone levels across Europe, highlighted, after statistical treatment, that a considerable fraction of the changes in ozone levels could be explained by meteorological effects and not directly by restriction measures that had been adopted.

Third, we highlight the importance of the time scale adopted in data collection as a key factor in influencing the results. It is a fact that the restriction measures in a location governed by the VOC-controlled regime (i.e., large city, metropolitan region-highly polluted) initially lead to an increase in the ozone concentration. However, this increase is only expected for, at most, the first few weeks. There is a consecutive decrease of this pollutant from the moment the evaluated ecosystem changes to the NOx-controlled regime. Therefore, if restriction measures are maintained for longer periods (more than a few weeks), it is natural, and expected, to observe a decrease in ozone levels in a given region when compared to the historical baseline.

Studies on this topic with data collection with a time scale of long periods eventually or found a decrease in ozone levels in the regions studied (Bekbulat et al. 2021; Miyazaki et al. 2021; Sathe et al. 2021; Steinbrecht et al. 2021; Querol et al. 2021; al. 2021) or found no significant change in the levels of this pollutant. In this context, the study developed by the German weather service Deutscher
Wetterdienst, with CIRES and NOAA co-authors, which included data collected from the northern hemisphere throughout the year 2020, pointed out that the ozone concentration in the free tropospheric (1- to $8-\mathrm{km}$ altitude) decreased by approximately 7\% from April to August when compared to its climatological average, this being the lowest value since the 2000s (Steinbrecht et al. 2021). Furthermore, Miyazaki et al. (2021), which collected and analyzed worldwide data throughout 2020 , found that the global total tropospheric ozone burden declined by approximately 2\% in May and June 2020. These two studies, of global character and strength, show us with clarity and certainty that ozone levels have decreased worldwide at the expense of COVID-19's lockdown measures.

Ultimately, some studies have shown caution and concern that if we are to take the COVID-19 lockdown measures as an analog of how air quality will respond to future reductions in emissions. These observations revealed that any air quality reduction strategies and policies should take into account the potential increase in ozone levels (Lee et al. 2020; Sicard et al. 2020; Grange et al. 2021). However, as discussed, we point out that these increases can be site-specific and/or on a limited time scale. So, although the dynamics of pollutants is a relevant aspect to be considered in future general policies, especially due to its health impacts, we must emphasize that, in the ozone case, successive decreases are expected after the ecosystem shifts to the NOx-controlled regime.

It is important to note that the wide range of reported air quality changes associated with COVID-19 responses around the world is not surprising. It provides an excellent example of the well-recognized complexity of the relationship between human activity, emissions, and ambient concentrations.

\section{Conclusion}

In conclusion, the trend does not mean unanimity! It is with this statement that we respond to the initial questioning of this discussion. For, although the trend presented by the vast majority of studies has been an increase in ozone levels, this trend was only regional, limited to the areas studied, being the global trend the opposite.

We raise awareness and concern with the way in which the initial "fever" of the behavior of air pollutants occurred. A fever that spread almost as fast as COVID-19 itself and that led many researchers to warn about the increase in ozone, but as time passed, it turned out that this was not the case. Furthermore, it is important to emphasize the behavior adopted by the tendency toward sampling highly populated 
areas, as this attitude could have caused biased estimations and disinformation.

Acknowledgements The authors thank the Coordenação de Aperfeiçoamento de Pessoal de Nível Superior, CAPES, for the Doctoral (RAT) scholarship.

Author contribution R.A.T. was responsible for conducting the discussion. F.M.R.S.J. supervised the study. All authors were responsible for analyzing and interpreting the data and writing the manuscript.

Funding This study was financed in part by the Coordenação de Aperfeiçoamento de Pessoal de Nível Superior-Brasil (CAPES)_Finance Code 001 and Conselho Nacional de Desenvolvimento Científico e Tecnológico (CNPq), Grant 310856/2020-5.

Data availability The datasets used and/or analyzed during the current discussion are available on the internet and from the corresponding author upon reasonable request.

\section{Declarations}

Ethics approval and consent to participate Not applicable.

Consent for publication Not applicable.

Competing interests The authors declare no competing interests.

\section{References}

Adams MD (2020) Air pollution in Ontario, Canada during the COVID-19 State of Emergency. Sci Total Environ 742:140516. https://doi.org/10.1016/j.scitotenv.2020.140516

Bao R, Zhang A (2020) Does lockdown reduce air pollution? Evidence from 44 cities in northern China. Sci Total Environ 731:139052. https://doi.org/10.1016/j.scitotenv.2020.139052

Berman JD, Ebisu K (2020) Changes in US air pollution during the COVID-19 pandemic. Sci Total Environ 739:139864. https://doi. org/10.1016/j.scitotenv.2020.139864

Bekbulat B, Apte JS, Millet DB, Robinson AL, Wells KC, Presto AA, Marshall JD (2021) Changes in criteria air pollution levels in the US before, during, and after Covid-19 stay-at-home orders: evidence from regulatory monitors. Sci Total Environ 769:144693. https://doi.org/10.1016/j.scitotenv.2020.144693

Chen LWA, Chien LC, Li Y, Lin G (2020) Nonuniform impacts of COVID-19 lockdown on air quality over the United States. Sci Total Environ 745:141105. https://doi.org/10.1016/j.scitotenv. 2020.141105

Chinazzi M, Davis JT, Ajelli M, Gioannini C, Litvinova M, Merler S, ... and Vespignani A (2020) The effect of travel restrictions on the spread of the 2019 novel coronavirus (COVID-19) outbreak. Science, 368(6489), 395-400. https://doi.org/10.1126/science. aba9757

Dantas G, Siciliano B, França BB, da Silva CM, Arbilla G (2020) The impact of COVID-19 partial lockdown on the air quality of the city of Rio de Janeiro, Brazil. Sci Total Environ 729:139085. https://doi.org/10.1016/j.scitotenv.2020.139085

Dentener F, Emberson L, Galmarini S, Cappelli G, Irimescu A, Mihailescu D, ... and van den Berg M (2020) Lower air pollution during COVID-19 lock-down: improving models and methods estimating ozone impacts on crops. Phil Trans R Soc A, 378(2183), 20200188. https://doi.org/10.1098/rsta.2020.0188

Diffenbaugh S, Field CB, Appel EA, Azevedo IL, Baldocchi DD, Burke M, ... and Wong-Parodi G (2020) The COVID-19 lockdowns: a window into the Earth System. Nat Rev Earth Environ, 1(9), 470-481. https://doi.org/10.1038/s43017-020-0079-1

ESA. (2020). Coronavirus lockdown leading to drop in pollution across Europe. Accessed 2020 August 05. https://www.esa.int/Applicatio ns/Observing_the_Earth/Copernicus/Sentinel-5P/Coronavirus_ lockdown_leading_to_drop_in_pollution_across_Europe

Fry CV, Cai X, Zhang Y, Wagner CS (2020) Consolidation in a crisis: patterns of international collaboration in early COVID-19 research. PLoS One 15(7):e0236307. https://doi.org/10.1371/ journal.pone. 0236307

Gaubert B, Bouarar I, Doumbia T, Liu Y, Stavrakou T, Deroubaix A ... and Brasseur GP (2021) Global changes in secondary atmospheric pollutants during the 2020 COVID-19 pandemic. J Geophys Res Atmos, 126(8), e2020JD034213. https://doi.org/10.1029/2020J D034213

Grange SK, Lee JD, Drysdale WS, Lewis AC, Hueglin C, Emmenegger L, Carslaw DC (2021) COVID-19 lockdowns highlight a risk of increasing ozone pollution in European urban areas. Atmos Chem Phys 21(5):4169-4185. https://doi.org/10.5194/acp-21-4169-2021

Hale T, Webster S, Petherick A, Phillips T, Kira B (2020) Oxford COVID-19 government response tracker (OxCGRT). https://covid tracker.bsg.ox.ac.uk. Accessed 12 Aug 2020

Keller CA, Evans MJ, Knowland KE, Hasenkopf CA, Modekurty S, Lucchesi RA, ... and Pawson S (2021) Global impact of COVID19 restrictions on the surface concentrations of nitrogen dioxide and ozone. Atmos Chem Phys, 21(5), 3555-3592. https://doi.org/ 10.5194/acp-21-3555-2021

Korhale N, Anand V, Beig G (2021) Disparity in ozone trends under COVID-19 lockdown in a closely located coastal and hillocky metropolis of India. Air Qual Atmos Health 14(4):533-542. https://doi.org/10.1007/s11869-020-00958-9

Lee JD, Drysdale WS, Finch DP, Wilde SE, Palmer PI (2020) UK surface NO 2 levels dropped by $42 \%$ during the COVID-19 lockdown: impact on surface O 3. Atmos Chem Phys 20(24):1574315759. https://doi.org/10.5194/acp-20-15743-2020

Menut L, Bessagnet B, Siour G, Mailler S, Pennel R, Cholakian A (2020) Impact of lockdown measures to combat Covid-19 on air quality over Western Europe. Sci Total Environ 741:140426. https://doi.org/10.1016/j.scitotenv.2020.140426

Miyazaki K, Bowman K, Sekiya T, Takigawa M, Neu JL, Sudo K, ... and Eskes H (2021) Global tropospheric ozone responses to reduced NOx emissions linked to the COVID-19 worldwide lockdowns. Sci Adv, 7(24), eabf7460. https://doi.org/10.1126/sciadv. abf7460

Nakada LYK, Urban RC (2020) COVID-19 pandemic: impacts on the air quality during the partial lockdown in São Paulo state, Brazil. Sci Total Environ 730:139087. https://doi.org/10.1016/j.scitotenv. 2020.139087

NASA (2020) Airborne nitrogen dioxide plummets over China. Accessed 2021 August 06. https://earthobservatory.nasa.gov/ images/146362/airborne-nitrogen-dioxide-plummets-over-china

Querol X, Massagué J, Alastuey A, Moreno T, Gangoiti G, Mantilla E, ... and Cornide MJ (2021) Lessons from the COVID-19 air pollution decrease in Spain: Now what?. Sci Total Environ, 779, 146380. https://doi.org/10.1016/j.scitotenv.2021.146380

Ordóñez C, Garrido-Perez JM, García-Herrera R (2020) Early spring near-surface ozone in Europe during the COVID-19 shutdown: meteorological effects outweigh emission changes. Sci Total Environ 747:141322. https://doi.org/10.1016/j.scitotenv.2020.141322

Sathe Y, Gupta P, Bawase M, Lamsal L, Patadia F, Thipse S (2021) Surface and satellite observations of air pollution in India during 
COVID-19 lockdown: implication to air quality. Sustain Cities Soc 66:102688. https://doi.org/10.1016/j.scs.2020.102688

Sicard P, De Marco A, Agathokleous E, Feng Z, Xu X, Paoletti E, ... and Calatayud V (2020) Amplified ozone pollution in cities during the COVID-19 lockdown. Sci Total Environ, 735, 139542. https:// doi.org/10.1016/j.scitotenv.2020.139542

Sillman S (1999) The relation between ozone, NOx and hydrocarbons in urban and polluted rural environments. Atmos Environ 33(12):1821-1845. https://doi.org/10.1016/S1352-2310(98) 00345-8

Steinbrecht W, Kubistin D, Plass-Dülmer C, Davies J, Tarasick DW, Gathen PVD, ... and Cooper OR (2021) COVID-19 crisis reduces free tropospheric ozone across the Northern Hemisphere. Geophys Res Lett, 48(5), e2020GL091987. https://doi.org/10.1029/ 2020GL091987

Tavella RA and Da Silva Júnior FMR (2020) COVID-19 and air pollution: what do we know so far?. VITTALLE-Revista de Ciências da Saúde, 32(1), 22-31. https://doi.org/10.14295/vittalle.v32i1. 11522
Tavella RA, Fernandes CLF, Penteado JO, De Lima Brum R, Florencio Ramires P, Coutelle Honscha L, ... and Da Silva Júnior FMR (2021) Unexpected reduction in ozone levels in a mid-size city during COVID-19 lockdown. Int J Environ Health Res, 1-14. https://doi.org/10.1080/09603123.2021.1917526

Tobías A, Carnerero C, Reche C, Massagué J, Via M, Minguillón MC, ... and Querol X (2020) Changes in air quality during the lockdown in Barcelona (Spain) one month into the SARS-CoV-2 epidemic. Sci Total Environ, 726, 138540. https://doi.org/10.1016/j. scitotenv.2020.138540

Zhang Y, Cai X, Fry CV, Wu M, Wagner CS (2021) Topic evolution, disruption and resilience in early COVID-19 research. Scientometrics 126(5):4225-4253. https://doi.org/10.1038/ s43017-020-0079-1

Publisher's note Springer Nature remains neutral with regard to jurisdictional claims in published maps and institutional affiliations. 